\title{
Burning mouth syndrome
}

\author{
Tara Renton BDS MDSc PHD FDS RCS FRACDS (OMS) \\ Professor in Oral Surgery \\ Kings College Dental Institute, Kings College Hospital, London SE5 9RS \\ tara.renton@kcl.ac.uk
}

\section{K E Y W O R D S}

Burning mouth syndrome, glossalgia, pain intractable, diagnosis, therapy, review, mechanisms

\section{S U M M A R Y P O I N T S}

- The aetiology of BMS remains an enigma, however novel evidence suggests a neuropathic basis, which may explain concomitant vulvodynia in some patients.

- The constant high level spontaneous chronic pain in BMS has significant functional and psychological repercussions for these patients.

- Cognitive behavioural therapy remains the sole evidence based management of this condition, whilst some patients respond to treatment with Tricyclic antidepressants, SSRIs or SNRIs, compliance with medication remains an issue due to pharma side effects.

- Increasing evidence suggests that there may be 3 subgroups that should be managed differently.

Burning mouth syndrome (BMS) is a chronic and intractable pain condition which is most common among middle aged and elderly women, affecting $1.5-5.5 \%$ of that population (1) and up to a million people in the USA (2). The International Association for the Study of Pain (IASP) has identified BMS as a distinct neuropathic orofacial pain condition characterised by bilateral burning oral mucosal pain, usually affecting the anterior two thirds of the tongue, that may comply with the anatomy of peripheral nerves and lacks any visible signs of mucosal pathology. BMS usually lasts for more than 6 months (3). The International Headache Society (IHS) (4) defines BMS as 'an intraoral burning sensation for which no medical or dental cause can be found.' The IHS diagnostic criteria state the need for constant pain, normal appearance of the oral mucosa and exclusion of any local/systemic diseases.

BMS is characterised by spontaneous onset, and continuous burning pain at moderate to severe intensity that may vary during the day and last several years $(5,6)$. Patients may display mechanical, thermal and taste (chili, curry, citrus) allodynia and often present with severe difficulty with oral function, having to remain on bland 'porridge' like diets. This intense ongoing oral pain severely affects the patients psychologically with high reported rates of depression (7).

\section{Aetiology and diagnosis of BMS}

BMS predominantly affects post menopausal women in their 5th-7th decade. Initiation can be spontaneous, or is sometimes associated with systemic factors such as diabetes, nutritional deficiencies, hormonal changes and psychological disorders, as well as local causes including: oral infections, allergies, galvanism, salivary gland dysfunction, salivary component changes and dental treatment, are of which are considered possible mechanisms (8). True BMS is a diagnosis of exclusion. In the presence of such systemic factors, it is known as either secondary BMS or is dismissed from the diagnosis of BMS completely until the systemic factors are resolved (8).

This has lead to a debate about the aetiology of BMS. Several studies have suggested various local, systemic and psychological precipitating factors, however, there is a lack of general agreement due to poor quality prospective studies and case reports. As stated by a Cochrane review, it is important to diagnose BMS only on exclusion of any such aetiological factors (9). These factors include:

1. Oral candidiasis. Candidal infections have been shown to induce a burning sensation (6). It is important to note, however, that treatment of the candidal infection has failed to relieve burning symptoms (10). 
2. Xerostomia (dry mouth). Prevalence of xerostomia in BMS patients ranges from $34 \%$ (11) to over $60 \%$. Some studies have failed to show a difference in saliva production compared with controls (12). Drug induced xerostomia is known to be a cause of dry mouth. Reduced saliva production in BMS patients taking antidepressants would be an understandable finding. In addition, BMS patients are known to have higher anxiety and depression scores, which increase the chances of a dry mouth (10).

3. Nutritional neuropathy. Grushka et al investigated the role of deficiencies of iron, folate, serum ferritin and vitamin B12 in 72 age and sex matched BMS patients, with 43 controls. These authors showed no significant differences between the groups (7). Some studies, however, have reported significantly lower levels of vitamin B12 in BMS patients (13-15). There have also been suggestions of deficiencies of vitamins B1, B2 and B6 causing BMS (16-19). More recently, deficiency in zinc levels has been demonstrated in BMS patients, with replacement therapy causing a decrease in pain, although not curing it completely (20).

4. Dysgeusia. Femiano et al reported up to two thirds of BMS patients with complaints of taste disturbances, especially persistent bitter and/or metallic tastes (21). Significantly different taste acuity in BMS patients has also been shown (7).

5. Mechanical factors. Poorly fitting prostheses causing local irritation and microtrauma have been suggested as a cause for BMS like symptoms (22). Conversely, it has been shown that denture replacement did not always relieve the symptoms, as is the case with supposedly allergic reactions to acrylic dentures $(13,23)$.

6. Parafunctional habits. Parafunctional activity is commonly seen in patients with increased levels of anxiety. There have been suggestions of such habits predisposing to BMS, but there have not been any controlled studies to support this (10).

7. Endocrine disorders. Certain systemic conditions have been implicated with BMS. Diabetes mellitus has been linked to BMS possibly due to reports of glossodynia in diabetics and also the risk of peripheral neuropathies, such as burning feet (24). Some studies suggest that poorly controlled diabetes can lead to BMS $(25,26)$ and that better glycaemic control can improve symptoms (27). Hypothyroidism has also been implicated in predisposing patients to BMS (28).

With BMS being more common in post-menopausal women, a decrease in oestrogen levels has been suggested as a cause for burning symptoms $(29,30)$. This has not been confirmed however, due to the lack of improvement following oestrogen replacement therapies (31).
Salivary cortisol levels have been investigated in BMS patients. Although they followed the same circadian cycle, salivary levels were generally higher in BMS than controls (32). Chronic anxiety in BMS has also been related to a dysregulation in the production of adrenal steroids (33).

8. Psychological disorders. BMS is stated to be 'conceptualised as a psychogenic physical continuum' (34), and over $50 \%$ of patients have been associated with psychological factors (35). Bergdhal et al (36), demonstrated a significantly higher score on the somatic anxiety, muscular tension and psychoasthenia scales in the BMS cohort and lower socialisation scores, compared to controls. Conversely, studies such as Carlson et al (37), have shown there to be no significant prevalence of psychiatric symptoms in BMS patients. It is important to note that patients with chronic pain commonly have psychologic dysfunction and this may be a result of the ongoing pain itself (38).

9. Helicobacter pylori (H.pylori) and gastrointestinal disease. Recent studies have suggested a correlation between the presence of H.pylori and burning sensations within the oral cavity (39). When tested for this bacterium, higher levels were found in BMS patients compared to controls $(39,40)$. In 2006 Brailo et al (41) found that $51.3 \%$ of BMS patients had gastritis and $12.3 \%$ showed evidence of H.pylori. In addition, BMS patients were found to be 3.2 times more likely to suffer from gastrointestinal disease (42). When all factors possibly contributing to BMS were analysed, gastrointestinal problems were most common in BMS patients (43).

10. Autoimmune. The roles of various cytokines in BMS have been suggested in the past. Simcic et al found salivary interleukins 2 and 6 (IL-2 and IL-6) to be elevated in correlation to the severity of the symptoms of BMS (44). Conversely, other studies have demonstrated a significant decrease in IL-2 (45) and IL-6 which was negatively correlated to chronic pain levels (46). More recently, no difference was found in salivary interleukin levels in BMS patients (47).

11. Contact hypersensitivity. Studies using patch testing on BMS patients has shown contact allergy not to play a significant role in its aetiology (48). Levels of IgE have also been investigated with no evidence to support its role (49). In addition, contact dermatitis has not been shown in BMS patients (50). 
12. Exclusion of other causes of peripheral neuropathy. Various secondary causes for peripheral neuropathies have been implicated and it is important to exclude these when diagnosing BMS. These causes include: diabetic peripheral neuropathy, inherited neuropathies, idiopathic small fibre sensory neuropathy, peripheral neuropathies associated with connective tissue disease, acquired amyloid polyneuropathy, neuropathy with renal failure, hereditary sensory autonomic neuropathy, sarcoid polyneuropathy, arsenic neuropathy, Fabry's disease, Coeliac's disease, HIV-related neuropathy, paraneoplastic sensory neuropathy, post traumatic peripheral sensory neuropathy, post herpetic neuropathy and demyelination in multiple sclerosis.

Routine diagnostic screening therefore should include exclusion of: nutritional neuropathies (serum Fe, ferritin, vitamins B1, B6, B12, folate and zinc), blood dyscrasias (FBC, WBC, RBC, MCV, ESR), liver disease (LFTs), thyroid function, renal disease (renal function test), autoantibody profile (ENAs and ANAs) and HBA1c.

In some specialist centres additional investigations may include candidal: infection (candida count), hormone imbalance (FSH, oestradiol, TSH, FT3, FT4) and, if the clinical history indicates, gastrointestinal disease (antibodies to H. pylori), allergy (serum total IgE, patch test for dental materials) and xerostomia (salivary flow rate). This would ensure that BMS is diagnosed correctly, as a diagnosis of exclusion.

\section{Pathogenesis of BMS}

The possible theories behind the cause of BMS include: a disorder of autonomic innervation and of oral blood flow (51), a sensory dysfunction associated with a small, and/or large fibre sensory neuropathy (52), a disruption in sensory pathways driven by changes in endocrine status at menopause (25) or a disruption of central sensory and modulatory pathways, including the spinal trigeminal nucleus and the striatum $(52,53)$. Recent studies have pointed to dysfunction of sensation as a possible cause of burning mouth syndrome and have demonstrated significant alterations in chemosensory and heat pain tolerance $(6,54)$ and elevated sensory and pain thresholds to argon laser stimulation (55) in BMS patients compared with control subjects. A recent study reports thin fibre dysfunction in $76 \%$ of 46 BMS patients when tested using quantitative sensory testing (QST) and the blink reflex (52). Small fiber sensory neuropathies predominantly occur in diabetic patients and present as 'burning feet'. Recent advances in understanding the aetiology, assessment and treatment of small fibre neuropathies include the suggestion that BMS may be a peripheral sensory small fibre neuropathy $(56,57)$. This is substantiated by a report that the total number of epithelial nerve fibres, innervation density within the fungiform papillae and connective tissue was significantly reduced in BMS $(n=12)$ patients compared with controls $(n=9)$ in association with axonal degeneration (58).
Several recent high profile studies of patients with neuropathic pain have shown that transmembrane ligand activated ion channels (TRPV) are up-regulated in skin or mucosa during hypersensitive states, and that sodium channels are up-regulated in skin associated with inflammatory conditions and with neuropathic pain subsequent to peripheral nerve injury in animal models (59). Demonstration of the loss of small diameter nerve fibres in the tongue epithelium explains thermal hypoesthesia $(58,60)$ and the increase in taste detection thresholds found in quantitative sensory testing. P2x3 (61) reactive receptors have been shown to be up-regulated, similarly $\mathrm{NaV}$ 1.7 in BMS (62). The changes in the presence and reactivity of these pain specific receptors may also explain in part the hypersensitivity of patients with BMS.

The role of taste in burning mouth syndrome is not straightforward as alterations in taste occur in as many as two thirds of patients and often include complaints of persistent tastes (bitter, metallic, or both) or changes in the intensity of taste perception. Dysgeusic tastes accompanying oral burning are often reduced by stimulation with food (6). Bartushok et al (63) state that there is an increased prevalence of so-called 'supertasters' (persons with enhanced abilities to detect taste) among patients with BMS. These supertasters may be more likely to be affected by burning pain syndrome because of their higher density of taste buds, each of which is surrounded by a basketlike collection of the pain neurones of the trigeminal nerve. This model would also explain the lack of effect of hormone replacement therapy once neural symptoms are established (27).

A recent review article on BMS (64) summarises that recent neurophysiologic, psychophysical, neuropathological and functional imaging studies may have elucidated multiple neuropathic mechanisms, mostly subclinical, acting at different levels of the neuraxis and contributing to the pathophysiology of primary BMS. As in neuropathic pain, decreased brain activation to heat stimuli has been demonstrated with fMRI in BMS patients (65).

Some authors conclude that the clinical diagnosis of primary BMS may encompass three distinct, subclinical neuropathic pain states that may overlap in individual patients.

- Subgroup 1 (50-65\%) is characterised by peripheral small diameter fibre neuropathy of intraoral mucosa.

- Subgroup 2 (20-25\%) consists of patients with subclinical lingual, mandibular, or trigeminal system pathology that can be dissected with careful neurophysiologic examination but is clinically indistinguishable from the other two subgroups.

- Subgroup 3 (20-40\%) fits the concept of central pain that may be related to hypofunction of dopaminergic neurones in the basal ganglia.

The neurogenic factors acting in these subgroups differ, and will require different treatment strategies. In the future, with proper use of diagnostic tests, BMS patients may benefit from interventions 
specifically targeted at the underlying pathophysiological mechanisms.

\section{Treatment of BMS}

At present there is no satisfactory treatment for these idiopathic orofacial pain conditions (66) and patients are destined to a future of recurrent hospital review appointments where an attempt is made to manage their intractable pain using a variety of antidepressants, anticonvulsants or drug combinations, all of which are ineffective and have undesirable side effects. Evidence based treatments include cognitive behavioural therapy and current pharmacological treatments, but these vary geographically. For example in some UK centres, tricyclic antidepressants are the main stay, whereas in others venlafaxine or pregabalin may be prescribed (67).

There is no doubt that currently these patients often remain poorly managed (66). With the development of orofacial pain services many clinicians are undertaking excellent research assessing peripheral and central pain pathways and even genetic analysis in these patients. It is hoped that with a better understanding of the aetiology and psychological impact of this disorder, partnered with the development of novel pharmacological interventions, improved management of BMS is on our horizon.

\section{REFERENCES}

1. Bergdahl M, Bergdahl J. Burning mouth syndrome: prevalence and associated factors. J Oral Pathol Med 1999;28:350-4.

2. Lipton JA, Ship JA, Larach-Robinson D. Estimated prevalence and distribution of reported orofacial pain in the United States. J Am Dent Assoc 1993;124(10):115-21.

3. Buchanan JA, Zakrzewska JM. Burning mouth syndrome. Clin Evid (Online). 2010 Jul 19;2010. pii: 1301

4. International Headache Society. Classification of BMS. Available from: http://ihs-classification.org/en/02.../04 teil3/13.18.05_facialpain.html

5. Grushka M. Burning mouth syndrome: pain disorder remains difficult to treat. Ont Dent 1987;64:26-30.

6. Grushka M. Clinical features of burning mouth syndrome. Oral Surg Oral Med Oral Path 1987;63(1):30-36.

7. Grushka M, Sessle BJ, Miller R. Pain and personality profiles in burning mouth syndrome. Pain 1987;28:169-84.

8. Granot M, Nagler RM. Association between regional idiopathic neuropathy and salivary involvement as the possible mechanism for oral sensory complaints. J Pain 2005;6(9):5817.
9. Zakrzewska JM, Forssell H, Glenny AM. Interventions for the treatment of burning mouth syndrome. Cochrane Database of Systematic Reviews 2005, Issue 1.

10. Sardella A. An up-to-date view on burning mouth syndrome. Minerva Stomatol 2007;56:327-40.

11. Klasser GD, Fischer DJ, Epstein JB. Burning mouth syndrome: recognition, understanding and management. Oral Maxillofac Surg Clin North Am 2008;20:255-71.

12. Lundy FT, Al-Hashimi I, Rees TD, Lamey PJ. Evaluation of major parotid glycoproteins in patients with burning mouth syndrome. Oral Surg Oral Med Oral Pathol Oral Radiol Endod 1997;83:252-8.

13. Lamey PJ, Lamb AB. Prospective study of aetiological factors in burning mouth syndrome. Br Med J (Clin Res Ed) 1988;296:1243-6.

14. Main DM, Basker RM. Patients complaining of a burning mouth. Further experience in clinical assessment and management. Br Dent J 1983;154:206-11.

15. Vucicevic-Boras V, Topic B, Cekic-Arambasin, Zadro R, Stavljenic-Rukavina. A lack of association between burning mouth syndrome and hematinic deficiencies. Eur J Med Res 2001;6:409-12.

16. Dutree-Meulenberg RO, Kozel MM, van Joost T. Burning mouth syndrome: a possible etiologic role for local contact hypersensitivity. J Am Acad Dermatol 1992;26:935-40.

17. Faccini JM. Oral manifestations of vitamin B12 deficiency. Br J Oral Surg 1968;6:137-140.

18. Hugoson A, Thorstensson B. Vitamin B status and response to replacement therapy in patients with burning mouth syndrome. Acta Odontol Scand 1991;49:367-75.

19. Brooke R, Seganski D. Etiology and investigation of the sore mouth syndrome. Dent J 1977;43:504-6.

20. Cho GS, Han MW, Lee B, Roh JL, Choi SH et al. Zinc deficiency may be a cause of burning mouth syndrome as zinc replacement therapy has therapeutic effects. J Oral Pathol Med 2010 Jul 2. [Epub ahead of print]

21. Femiano F, Lanza A, Buonaiuto C, Gombos F, Cirillo N. Burning mouth disorder (BMD) and taste: A hypothesis. Med Oral Patol Cir Bucal 2008;13:E470-4.

22. Lopez-Jornet P, Camacho-Alonso F, Andujar-Mateos P, Sanchez-Siles M, Gomez-Garcia F. Burning mouth syndrome: Update. Med Oral Patol Oral Cir Bucal 2010;15(4):e562-8. 
23. Yontchev E, Meding B, Hedegård. Contact allergy to dental materials in patients with orofacial complaints. Br J Oral Rehabil 1986 Mar;13(2):183-90.

24. Moore PA, Guggenheimer J, Orchard TJ. Burning mouth syndrome and peripheral neuropathy in patients with type 1 diabetes mellitus. Diab Complic 2007;21(6):397-402.

25. Basker RM, Sturdee DW, Davenport JC. Patients with burning mouths. A clinical investigation of causative factors, including the climacteric and diabetes. Br Dent J 1978;145:9-16.

26. Gibson J, Lamey PJ, Lewis M, Frier B. Oral manifestations of previously undiagnosed non-insulin dependent diabetes mellitus. J Oral Pathol Med 1990;19(6):284-7.

27. Goss AN. Sore tongue. NZ Dent J 1973;69(317):194-201.

28. Femiano F, Gombos F, Esposito V, Nunziata M, Scully C. Burning mouth syndrome (BMS): evaluation of thyroid and taste. Med Oral Patol Oral Cir Bucal 2006;11(1):E22-5.

29. Wardrop RW, Hailes J, Burger H, Reade PC. Oral discomfort at menopause. Oral Surg Oral Med Oral Path 1989;67:535-40.

30. Santoro V, Caputo G, Peluso F. Clinical and therapeutic experience in twenty eight patients with burning mouth syndrome. Minerva Stomatol 2005;54(9):489-96.

31. Tarkila L, Linna M, Tiitinen A, Lindqvist C, Meurman JH. Oral symptoms at menopause: the role of hormone replacement therapy. Oral Surg Oral Med Oral Pathol Oral Radiol Endod 2001;92:276-80.

32. Amenábar JM, Pawlowski J, Hilgert JB, Hugo FN, Bandeira $\mathrm{D}$ et al. Anxiety and salivary cortisol levels in patients with burning mouth syndrome: case-control study. Oral Surg Oral Med Oral Pathol Oral Radiol Endod 2008;105(4):460-5.

33. Woda A, Dao T, Gremeau-Richard C. Steroid dysregulation and stomatodynia (burning mouth syndrome). J Orofac Pain 2009;23(3):202-10.

34. Freeman R. A psychotherapeutic case illustrating a psychogenic factor in burning mouth syndrome. Br J Psychother 1993;10:220-5.

35. Browning S, Hislop S, Scully C, Shirlaw P. The association between burning mouth syndrome and psychosocial disorders. Oral Surg Oral Med Oral Path 1987;64(2):171-4.

36. Bergdahl J, Anneroth G, Perris H. Cognitive therapy in the treatment of patients with resistant burning mouth syndrome: a controlled study. J Oral Pathol Med 1995;24:213-5.
37. Carlson CR, Miller CS, Reid KL. Psychosocial profiles of patients with burning mouth. J Orofac Pain 2000;14(1):59-64.

38. Grushka M, Bartoshuk LM. Burning mouth syndrome and oral dysesthesias. Can J Diagnos 2000;June:99-109.

39. Adler I, Denninghoff VC, Alvarez MI, Avagnina A, Yoshida R, Elsner B. Helicobacter pylori associated with glossitis and halitosis. Helicobacter 2005;10(4):312-7.

40. Gall-Troselj K, Mravak-Stipetić M, Jurak I, Ragland WL, Pavelić J. Helicobacter pylori colonization of tongue mucosa-increased incidence in atrophic glossitis and burning mouth syndrome (BMS). J Oral Pathol Med 2001;30(9):560-3.

41. Brailo V, Vueiaeeviae_Boras V, Alajbeg I, Lukenda J, Urkoviae M. Oral burning symptoms and burning mouth syndromesignificance of different variables in 150 patients. Med Oral Patol Oral Cir Bucal 2006;11:E252-5.

42. Lamey PJ, Lamb AB. Prospective study of aetiological factors in burning mouth syndrome Br Med J (Clin Res Ed) 1988;296:1243-6.

43. Netto FO, Diniz IM, Grossmann SM, de Abreu MH, do Carmo MA, Aguiar MC. Risk factors in burning mouth syndrome: a case-control study based on patient records. Clin Oral Investig 2010 May 4. [Epub ahead of print]

44. Simcic D, Pezeil-Ribaric S, Grzic R, Horvat J, Brumini G, Muhvic-Urek M. Detection of salivary interleukin 2 and interleukin 6 in patients with burning mouth syndrome. Mediators Inflamm 2006;(1):54632.

45. Pekiner FN, Demirel GY, Gumru B, Ozbayrak S. Serum cytokine and $\mathrm{T}$ regulatory cell levels in patients with burning mouth syndrome. J Oral Pathol Med 2008;37(9):528-34.

46. Chen Q, Xia J, Lin M, Zhou H, Li B. Serum interleukin-6 in patients with burning mouth syndrome and relationship with depression and perceived pain. Mediators Inflamm 2007;45327.

47. Suh KI, Kim YK, Kho HS. Salivary levels of IL-1 beta, IL-6, IL-8 and TNF-alpha in patients with burning mouth syndrome. Arch Oral Biol 2009;54(9):797-802.

48. Vergili A, Corazza M, Trombelli L, Arcidiacono A. Burning mouth syndrome: the role of contact hypersensitivity. Acta Derm Venereol 1996;76(6):488-90.

49. Campisi G, Di Liberto C. Role of total IgE in unspecified burning oral symptoms. Serum and salivary comparative levels in a case-control study. Minerva Stomatol 2003;52(7-8):38191. 
50. Helton J, Storrs F. The burning mouth syndrome: lack of a role for contact urticaria and contact dermatitis. J Am Acad Dermatol 1994;31:201-5.

51. Heckmann SM, Heckmann JG, HiIz MJ, Popp M, Marthol H et al. Oral mucosal blood flow in patients with burning mouth syndrome. Pain 2001;90:281-6.

52. Forssell H, Jaaskelainen S, Tenovuo O, Hinkka S. Sensory dysfunction in burning mouth syndrome. Pain 2002;99:41-7.

53. Gao S, Wang Y, Wang Z. Assessment of trigeminal somatosensory evoked potentials in burning mouth syndrome. Chin J Dent Res 2000;3(1):40-6.

54. Grushka M, Sessle BJ, Howley TP. Psychophysical assessment of tactile, pain and thermal sensory functions in burning mouth syndrome. Pain 1987;28:169-84.

55. Svensson P, Bjerring P, Arendt-Nielson L, Kaaber S. Sensory and pain thresholds to orofacial argon laser stimulation in patients with chronic burning mouth syndrome. Clin J Pain 1993;9:207-15

56. Lauritano D, Spadari F, Formaglio F, Zambellini Artini M, Salvato A. Etiopathogenic, clinical-diagnostic and therapeutic aspects of the burning mouth syndrome. Research and treatment protocols in a patient group. Minerva Stomatol 1998;47(6):239-51.

57. Lauria G, Majorana A, Borgna M, Lombardi R, Penza P et al. Trigeminal small-fiber sensory neuropathy causes burning mouth syndrome. Pain 2005;18:591-7.

58. Yilmaz Z, Renton T, Yiangou Y, Zakrzewska J, Chessell IP et al. Burning mouth syndrome as a trigeminal small fibre neuropathy: Increased heat and capsaicin receptor TRPV1 in nerve fibres correlates with pain score. J Clin Neurosci 2007;14(9):864-71. Epub Jun 19.

59. Coward K, Plumpton C, Facer P, Birch R, Carlstedt T et al. Immunolocalization of SNS/PN3 and Nav1.9 sodium channels in human pain states. Pain 2000;85:41-50.

60. Kaplan I, Levin T, Papoiu AD, Patel N, Patel T et al. Thermal sensory and pain thresholds in the tongue and chin change with age, but are not altered in burning mouth syndrome. Skin Res Technol 2011;17(2):196-200.

61. Beneng K, Yilmaz Z, Yiangou Y, McPharland H, Anand P, Renton T. Sensory purinergic receptor P2X(3) is elevated in burning mouth syndrome. Int J Oral Maxillofac Surg 2010 Apr 24.
62. Beneng K, Renton T, Yilmaz Z, Yiangou Y, Anand P. Sodium channel Nav1.7 immunoreactivity in painful human dental pulp and burning mouth syndrome. BMC Neurosci 2010;11(1):71. [Epub ahead of print]PMID: 20529324.

63. Bartoshuk LM, Grushka M, Duffy VB, Fast L, Lucchina L et al. Burning mouth syndrome: damage to CN VII and pain phantoms in CN V [Abstract]. Chem Senses 1999;24:609.

64. Jääskeläinen SK. Pathophysiology of primary burning mouth syndrome. Clin Neurophysiol 2011; Oct 24.

65. Albuquerque RJ, de Leeuw R, Carlson CR, Okeson JP, Miller CS, Andersen AH. Cerebral activation during thermal stimulation of patients who have burning mouth disorder: an fMRI study. Pain 2006;122(3):223-34. Epub 2006 Apr 24.

66. Zakrzewska JM. The burning mouth syndrome remains an enigma [Editorial]. Pain 1995;62:253-7.

67. Woda A, Navez ML, Picard P, Gremeau C, Pichard-Leandri E. A possible therapeutic solution for stomatodynia (burning mouth syndrome). J Orofac Pain 1998;12:272-8. 